\title{
REVIEW
}

\section{Year in review 2012: Critical Care -management}

\author{
Abhijit Duggal ${ }^{* 1}$ and Gordon Rubenfeld ${ }^{2,3}$
}

\begin{abstract}
Outcomes research plays a key role in defining the effects of medical care in critical care. Last year Critical Care published a number of papers that evaluated patient-centered and policy-relevant outcomes. We present this review article focusing on key reported outcomes associated with severe community-acquired pneumonia, mortality associated with decisions regarding triage to the $\mathrm{ICU}$, and both short-term and long-term mortality associated with ICU admissions. We further analyze the literature, assessing outcomes such as quality of life and the psychological burden associated with critical care. We also reviewed processes of care, and studies looking at cost analysis of treatment associated with critical care.
\end{abstract}

\section{Introduction \\ Unlike other medical research, key variables evaluating disease, the patient population and therapies are hetero- geneous and difficult to define in critical care research [1]. With respect to critical care research, both short- term outcomes and long-term outcomes hold a key place in understanding the impact of our interventions. Last year Critical Care published a number of highly accessed, original articles in critical care research. We present this review article focusing on key reported outcomes including mortality, patient-assessed outcomes such as quality of life, processes of care and cost analysis.}

\section{Outcomes associated with severe community- acquired pneumonia}

Estimates indicate that $10 \%$ of the 500,000 patients hospitalized with community-acquired pneumonia are admitted to the ICU [2]. Delay in the recognition of severe community-acquired pneumonia is associated with increased mortality. Clinical prediction to assess

*Correspondence: duggala2@ccf.org

'Medical Intensive Care Unit, Respiratory Institute, Cleveland Clinic Foundation,

9500 Euclid Avenue, Cleveland, OH 44195, USA

Full list of author information is available at the end of the article severe community-acquired pneumonia is hampered not only by the absence of a unique definition for severe community-acquired pneumonia but also by the inclusion of ICU admission as a variable in the prediction model in many cases [3,4]. Marti and colleagues studied 11 different prediction scores based on 20 variables to identify community-acquired pneumonia patients requiring ICU admission [5]. Older prediction scores (Pneumonia Severity Index and CURB-65) were not sensitive in identifying the need for ICU admission. Newer generation prediction rules such as those of the American Thoracic Society/Infectious Diseases Society of America 2007 were much more specific in predicting the need for ICU admission. The American Thoracic Society/Infectious Diseases Society of America 2007 minor criteria along with newer unvalidated scores such as severe community-acquired pneumonia performed the best and had an area under the curve of 0.85 in predicting ICU admission. Although the new prediction rules performed better, their lack of specific test characteristics to help in bedside decisions for ICU admissions makes their use limited in clinical practice [5].

The association of statins with the risk of developing pneumonia and any reduction in mortality associated with severe community-acquired pneumonia has had conflicting results [6,7]. Nielson and colleagues used data from the Danish national registry to perform a population-based case-control study to answer this debate [8]. They evaluated 70,914 hospitalized pneumonia cases, and an unadjusted analysis using matching for age and sex showed an odds ratio (OR) of 1.17 (95\% confidence interval $(\mathrm{CI})=1.14$ to 1.21 ) associating current statin use with a risk for developing pneumonia requiring hospitalization. After adjustment for confounders, the OR was reduced to 0.80 ( $95 \% \mathrm{CI}=0.77$ to 0.83 ). This reduction in the rate of hospitalization was seen in all subgroups of current statin users, but this effect was lost in former statin users. The authors also analyzed the 30-day mortality of hospitalized patients and revealed a $27 \%$ decrease in mortality associated with pneumonia in current statin users (hazard ratio $=0.73,95 \% \mathrm{CI}=0.67$ to 0.79 ). These results are in line with a number of other studies, but a few recent studies have not shown this protective effect of statin use, and the question of a 
healthy user effect in statin users has been proposed [9]. The authors perform a very well-structured study with careful consideration to address any residual confounding, and bring forward the possibility of a pleiotropic effect of statin use on both the risk of hospitalization and the overall outcomes associated with pneumonia. The important questions of whether current statin users admitted to the ICU should have these drugs continued or whether statins should be initiated at the time of ICU admission ultimately await the results of ongoing trials.

Kojicic and colleagues evaluated a cohort of 596 patients to study the frequency and associated outcomes of acute lung injury [7] in patients with microbiologically proven pneumonia. Of these patients, $28.7 \%$ developed acute lung injury and the risk was higher in hospital pneumonia (38.5\%) and healthcare-associated pneumonia (31.6\%) when compared with community-acquired pneumonia (21.8\%) [10]. The patients who developed acute lung injury associated with pneumonia had a markedly higher risk of hospital mortality even after adjustment for baseline severity of illness and comorbidities (OR $=9.7,95 \% \mathrm{CI}=6.0$ to 15.9). The authors also performed a nested case-control study with matching for site of isolation and the kind of pathogen to identify variables associated with the development of acute lung injury. After adjustment for baseline differences and the Pneumonia Severity Index, the use of inappropriate antimicrobial treatment $(\mathrm{OR}=3.2,95 \% \mathrm{CI}=$ 1.3 to 8.5$)$ and transfusions ( $\mathrm{OR}=4.8,95 \% \mathrm{CI}=1.5$ to 19.6) were independently associated with the development of acute lung injury. The authors performed a posthoc analysis that, after adjustment for these variables, showed the use of statins was associated with a decreased risk of developing acute lung injury. These results present potential clinical targets for preventing progression to acute respiratory distress syndrome (ARDS) in patients with pneumonia.

\section{Decisions regarding triage to the ICU and associated mortality}

There has been a significant increase in the demand for critical services worldwide [11]. This increased demand places a huge constraint on bed provision for patients requiring these services [12]. Many patients are transferred to different hospitals based on capacity reasons [13]. Earlier studies reported significant adverse events associated with interhospital transfer [14], but recent data have shown that adverse events are extremely rare during interhospital transfer of critically ill patients [15]. Previous studies have also shown that transferred patients have longer ICU stays and a higher mortality when compared with nontransferred patients [13]. Barratt and colleagues performed a propensity-matched analysis of patients transferred to a different ICU for nonclinical reasons defined as lack of bed capacity within 48 hours of admission to predict the OR for hospital mortality [16]. Despite the availability of guidelines to contain nonclinical transfers in the United Kingdom, the authors found a significant degree of variation in practice across the 28 critical care networks in England and Wales that they included in their analysis (range of adjusted $\mathrm{OR}=0.29$ to 4.90 ). When they matched controls based on propensity to these nonclinical transfers, however, they did not find a difference in mortality among these two groups (relative risk $=1.01,95 \% \mathrm{CI}=0.87$ to $1.16 ; P=$ 0.94). Patients who were transferred to other hospitals did receive an extra 3 days of critical care as compared with patients who were not transferred [16].

An alternative strategy to interhospital transfer is to manage patients on site or in other locations such as operating theaters until an ICU bed becomes available. In a study from the United Kingdom, O'Callaghan and associates studied the effect of delays in ICU admission when patients were cared for in operating theater suites [17]. They evaluated 1,609 patients, of which 149 patients (9.3\%) had a delayed admission to the ICU. The median duration of delay was 6 hours (interquartile range $=4.5$ to 10 hours). The authors did not see any differences in mortality and lengths of stay in the ICU and hospital as a result of delays in the operating suites. But they did see much higher rates of respiratory failure $(25.5 \%$ vs. $15.6 \%$, $P<0.01)$ in this group of patients when compared with the no-delay group in the first 24 hours after ICU referral. Lack of ICU beds is becoming a big problem in the United Kingdom and other western countries; Metcalfe and associates reported that $14 \%$ of ICU admissions in the United Kingdom were refused because of lack of availability of beds [18]. Owing to these issues around bed constraints, novel interventions such as suggested by O'Callaghan can help provide better care for critically ill patients. A large reason for the lack of difference in outcomes in this study might be due to the fact that, unlinked with previously published data, two anesthetic trainees managed the patients with senior input from an ICU specialist while they were awaiting ICU transfer. These results might therefore be a reflection of the importance of appropriate care for critically ill patients even in non-ICU settings. Of course, the safety of this approach depends on access to appropriate clinicians outside the ICU, which may not exist everywhere. The authors did not evaluate the effects of using alternate locations for intensive care on providing other hospital operative or emergency services.

The impact of bed occupancy for critically ill patients is perhaps seen most dramatically in disease outbreaks, such as the recent H1N1 pandemic [19]. This need is more pronounced when a critical threshold is achieved and usual ICU care for elective procedures and so forth 
has to be discontinued [20]. Richard and associates used an online screening registry to study the patterns of ICU bed occupancy in different ICUs in France during the H1N1 pandemic [21]. They defined the critical threshold as an occupancy rate $>15 \%$ by patients with the flu at any given time. The study showed that there was a great variation in the peak occupancy based on the geographical region, on the time and on whether a hospital was university or nonuniversity affiliated during the influenza pandemic. Studies of this nature may help inform the development of electronic triaging and communication systems that will assist with real-time data analysis to help distribute ICU resources much more effectively, and can be an effective tool in data notification for public health surveillance agencies.

Medical emergency teams are used to provide expert critical care services for clinical deterioration promptly in non-ICU wards. There is a large variability in the roles of, composition of and services provided by these teams. Recent studies have questioned the impact of such teams on clinical outcomes [22]. Implementation of medical emergency teams is a complex, multistep process, however, and it is thought that a large driver of the negative results in studies is associated with difficulty in changing provider behavior and processes of care in hospital settings [23]. Tobin and associates studied the impact of introduction of a medical emergency team on hospital mortality and evaluated individual hospital admissions over a 10-year period in 12 different hospitals in Australia [24]. They found that the benefit of medical emergency teams was delayed, and the benefit became apparent only after a medical emergency team had been active for more than 2 years in a hospital setting. After accounting for confounders, the mortality was not statistically different from that in the period before the medical emergency team in the first 2 years $(\mathrm{OR}=0.99$, $95 \% \mathrm{CI}=0.97$ to 1.02 ), but hospital mortality decreased the longer the team had been in place in any institution $(\mathrm{OR}=0.93,95 \% \mathrm{CI}=0.91$ to 0.96 for 2 to 4 years; and $\mathrm{OR}=0.90,95 \% \mathrm{CI}=0.88$ to 0.92 where the system had been in place for more than 4 years). Similar to previously published data, this study again highlighted the fact that there is a large variation in the composition and role of the medical emergency teams. But more importantly the authors have shown that changes in outcomes associated with these teams took time to become apparent, but these improvements persist once hospital processes and culture are changed.

\section{Gender and ICU mortality}

Previously published data have shown that that women needing ICU care are less likely to receive aggressive treatment compared with men [25]. Studies from both Canada and Europe have shown that there are gender-based differences in mortality favoring men $[26,27]$. Mahmood and colleagues analyzed the Acute Physiology and Chronic Health Evaluation (APACHE) IV database to evaluate whether similar differences existed in American ICUs [28]. After adjustment for potential confounders, there was no statistical difference in mortality between the two groups (adjusted $\mathrm{OR}=0.98$, $95 \% \mathrm{CI}=0.95$ to 1.02 ). Interestingly the authors found a statistically significant interaction between gender and age, so they performed stratified analyses. After the stratification they found for patients $<50$ years of age that women had a lower mortality compared with men (adjusted OR $=0.83,95 \% \mathrm{CI}=0.76$ to 0.91 ). Among patients $\geq 50$ years of age there was no statistically significant difference in the ICU mortality between men and women. Similar to previous studies, however, they did see that men were more likely to receive mechanical ventilation, emergent surgery and coronary artery bypass grafting. This study points out that even though there is no difference in mortality between genders, there is variability in the provision of care for women when compared with men. Future research therefore needs to focus on understanding why this apparent difference in treatment intensity exists.

\section{Light and the ICU}

In a very interesting study Castro and associates evaluated whether exposure to light both prior to and during critical illness might influence mortality [29]. They studied the impact of variation in regional photoperiod and insolation on winter immunoenhancement in these patients. After adjustment for confounders a 1-hour decrease in a cumulative 28-day photoperiod was associated with a significant decrease in hospital mortality (adjusted OR $=0.997,95 \% \mathrm{CI}=0.994$ to $0.999 ; P=0.03$ ). Patients in the lowest quartile of the cumulative 28-day photoperiod had lower mortality risk compared with patients in the highest quartile (adjusted OR $=0.69,95 \%$ $\mathrm{CI}=0.47$ to $1.01 ; P=0.06$ ). There was no difference in the exposure to light after a patient was admitted to the ICU. The authors postulated that in the ICU the exposure light is of low intensity with minimal diurnal variation, and perhaps future studies need to manipulate light insolation and wavelength to study any biological effects in these artificial settings.

\section{Delirium in the ICU}

Delirium in critically ill patients is associated with increased morbidity and mortality [30,31]. Unfortunately standard clinical evaluation underestimates the prevalence of this diagnosis and recognition of delirium remains a diagnostic challenge in this patient population. The Confusion Assessment Method for the Intensive Care Unit and the Intensive Care Delirium Screening Checklist 
are the most commonly used scales for delirium evaluation in the ICU [32]. In a recent meta-analysis the pooled values of sensitivity (80.0\%) and specificity (95.9\%) for the Confusion Assessment Method for the Intensive Care Unit to diagnose delirium in critically ill patients were very impressive. The area under the summary receiver operating characteristics curve was 0.97 , which suggests excellent accuracy for this test. The equivalent value for the Intensive Care Delirium Screening Checklist was 0.89, which suggests good accuracy for this test as well [33]. The results of this meta-analysis thus support the use of the Confusion Assessment Method for the Intensive Care Unit or the Intensive Care Delirium Screening Checklist as screening tools for delirium in critically ill patients. Also, based on the high specificity of the Confusion Assessment Method for the Intensive Care Unit, this is an excellent diagnostic tool for evaluating delirium in ICU patients. Of course, the clinical value of identifying delirious patients by screening has yet to be demonstrated because a specific intervention that offers the best therapy, particularly for quiet delirium, has not been identified.

Owing to the risks associated with the development of delirium in critically ill patients, addressing modifiable risk factors such as sedation management, minimization of sleep disruption and early mobilization of patients has become part of ICU management [34,35]. Van Rompaey and colleagues performed a randomized trial to see whether the provision of earplugs to ICU patients could affect the development of confusion or delirium in critically ill patients. They studied 136 patients and followed the intervention and control groups over a period of 5 days [36]. The authors evaluated the development of confusion or delirium using the Neelon and Champagne Confusion Scale score in patients of both groups. They found similar rates of delirium (19\% vs. $20 \%$ ) in the two groups, but the patients with earplugs developed mild confusion at a much lower rate (15\% vs. $40 \%)$ compared with the control group. These patients also reported significantly better sleep during their first night in the ICU. The onset of delirium in the intervention group also occurred later during the hospital course. A Cox regression analysis revealed that the use of earplugs reduced the rate of delirium by $53 \%$ (hazard ratio $=0.47$, $95 \% \mathrm{CI}=0.27$ to 0.82 ). In a multivariable model the rate of delirium was associated with age, Sequential Organ Failure Assessment score and a history of smoking. This study points out to the fact that targeted prevention can have a significant impact on outcomes in critically ill patients.

There are convincing data available that prove analgesia and sedation protocols improve the duration of mechanical ventilation, the length of ICU stay and survival in critically ill patients $[34,37]$. However, there is a wide variability in the implementation and perhaps even in the content of these protocols in different ICU settings $[38,39]$. Dale and colleagues were able to demonstrate that higher volume teaching hospitals that were members of a larger hospital network were more likely to develop sedation, analgesia and delirium order sets, and also were more likely to follow appropriate guidelines to develop these protocols [40].

\section{Long-term outcomes}

Survivors of critical illness are at risk for both physical and psychological morbidity even after hospital discharge [41]. These complications are a manifestation of the underlying injury, associated multiorgan failure and debilitation from the long ICU and hospital stay [42].

\section{Long-term outcomes and health-related quality of life after ICU discharge}

Neuropsychological and cognitive assessments and quality-of-life measures indicate that there is persistent morbidity after discharge from the ICU [41], but there are few data on long-term outcomes and health-related quality of life (HRQoL) in patients undergoing specific ICU-related procedures such as renal replacement therapy and extracorporeal life support [43,44]. Vaara and associates looked at the HRQoL and 6-month mortality in critically ill patients in Finland who underwent renal replacement therapy, as compared with the general ICU population. The HRQoL was assessed using the EQ-5D instrument [45]. Hospital mortality (35.0\% vs. $15.5 \%, P<0.001)$ and 6-month mortality $(49.4 \%$ vs. 27.8, $P<0.001)$ of patients undergoing renal replacement therapy were significantly higher compared with nonrenal replacement therapy patients. But the quality of life based on the EQ-5D at 6 months was similar in both groups. The severity of disease and overall mortality rates that were reported were much lower than those reported in previous studies. Also the results for the HRQoL have to be interpreted carefully, as follow-up for these patients was reported to be $<50 \%$.

Functional disability after ARDS is well documented [42]. The use of extracorporeal membrane oxygenation in ARDS with refractory hypoxemia has been associated with improved outcomes [46]. There are limited data for the effects of extracorporeal membrane oxygenation on long-term outcomes and HRQoL in critically ill patients [44]. Hodgson and colleagues compared the HRQoL of Australian extracorporeal membrane oxygenation survivors with published data on HRQoL in patients with ARDS with and without the use of extracorporeal membrane oxygenation [47]. They evaluated 21 patients, who received extracorporeal membrane oxygenation for a median of 10.6 (3.6 to 15.8 ) days: $86 \%$ survived to hospital discharge, and 15 patients consented to 
follow-up for long-term quality-of-life assessment and outcomes. Similar to previous data in ARDS patients, this cohort had significantly lower HRQoL scores on a 36-item Short Form assessment compared with the general Australian population. When these patients were compared with other studies looking at these outcomes in ARDS patients, the individuals that underwent extracorporeal membrane oxygenation reported reduced HRQoL in vitality and social functions. Further studies with adequate sample sizes and appropriate follow-up are needed before we can fully understand the impact of extracorporeal membrane oxygenation or dialysis on HRQoL and whether the observed effect is due to the treatment or to the underlying severity of illness.

\section{Psychological morbidity after ICU discharge}

Survivors of critical illness have a high incidence of posttraumatic stress disorder (PTSD), depression and anxiety in the months following intensive care [48,49]. These poor psychological outcomes might result due to a number of clinical, psychological and chronic health risk factors. Wade and colleagues used a validated questionnaire on 100 ICU survivors to study the prevalence of PTSD, anxiety and depression 3 months after ICU admission [50]. At follow-up, 27.1\% of the patients had probable PTSD, 46.3\% probable depression and 44.4\% anxiety. Duration of sedation was the strongest clinical risk factor associated with PTSD, while use of benzodiazepines was associated with the development of depression. Use of inotropes or vasopressors correlated with anxiety at 3 months. The analysis also pointed towards acute psychological reactions as potential mediators for these clinical risk factors. After adjustment, psychological history and the mood of the patient in the ICU were associated with both depression and PTSD [50].

Strikingly high rates of psychological morbidity were found in this cohort of intensive care survivors. These findings suggest that psychological interventions, along with pharmacological modifications, could help reduce poor outcomes, including PTSD, after intensive care. Schandl and colleagues studied the gender differences in long-term symptoms of post-traumatic stress anxiety and depression in an ICU follow-up program with those not offered such help. The authors used the Impact of Event Scale for post-traumatic stress and the Hospital Anxiety and Depression Scale for anxiety and depression [51]. Women without a follow-up had higher Impact of Event Scale scores than men without a follow-up. After adjustment for confounders, women in the intervention groups reported significantly lower Impact of Event Scale scores when compared with the control group. Women in the control group reported higher Impact of Event Scale scores than men in the control group (median $31 \mathrm{p}-$ points vs. 10 p-points, $P<0.01)$. This study highlights that women are more likely to develop psychological problems after ICU admission, but are also more likely than men to seek therapy for their symptoms [51].

\section{Prognostication scores and sepsis}

Prognostic application of scoring systems in critical care is limited [52]. These systems rely on average risk associated with a population, so their ability to predict outcomes in individual patients is inadequate [53]. Recent studies suggest that soluble urokinase plasminogen activator receptor may be a marker of poor outcomes in septic patients [54]. Based on this research, a multicenter study from Greece analyzed the use of soluble urokinase plasminogen activator receptor in association with APACHE II to develop a new prognostication score to provide information regarding the risk of death in septic patients [55]. The authors found that the addition of this receptor to APACHE II did not change the receiver operator characteristics for prognosis of adverse outcomes in septic patients. But an APACHE II score $\geq 17$ and a soluble urokinase plasminogen activator receptor $\geq 12$ were independently associated with unfavorable outcomes in these patients. The authors therefore used regression analysis to develop a prognostication rule. They developed four strata based on these values, and found that the utilization of soluble urokinase plasminogen activator receptor was seen in high-risk patients not detected by APACHE II scores. Among patients with APACHE II score $\leq 17$ the OR for death in patients with soluble urokinase plasminogen activator receptor $\geq 12$ was 3.62. An independent cohort of Swedish patients confirmed prognostication by this rule [55].

\section{Resource allocation}

Nurse practitioners and physician assistants are staffing an ever-increasing number of ICUs in the USA [56]. Physicians supervise these physician assistants and nurse practitioners and in turn they provide patient care service including, but not limited to, history-taking, physical examination, implementing protocols and performing procedures [56]. In an interesting study by Carpenter and colleagues the authors evaluated how these practitioners allocated their time between patient care activities and nonpatient care activities [57]. The study looked at the pre-intervention characteristics of the nurse practitioners and physician assistants, and based on billing information the average practitioner spent $53 \%$ (range 21 to $95 \%$ ) of their time on patient care. The authors provided an incentive to these physician assistants and nurse practitioners, and data collection in the follow-up period revealed a $31 \%$ absolute improvement in documentation for patient care time. The authors postulate that this study demonstrates that these affiliates spend up to $85 \%$ of their time on patient care-related activities [57]. The 
rest of the time is spent rounding, providing sign-outs and performing chart reviews. This study provides some vital information for ICUs that plan to introduce nurse practitioners and physician assistants in their ICUs. These data need to be put into context, however, because this study was carried out in a wide variety of coverage models, and nurse practitioner and physician assistant staffing was dependent in many cases on the availability of residents. Also these data are self-reported, and there was either inadequate or missing documentation for most of these practitioners until an incentive was introduced. Therefore it is difficult to say that these roles would remain unchanged over longer periods of time.

\section{Cost analysis of total parenteral nutrition}

The results from the Impact of Early Parenteral Nutrition Completing Enteral Nutrition in Critical Illness (EPaNIC) trial showed that an early parenteral nutrition strategy was less effective than late parenteral nutrition because it resulted in higher rates of new ICU infections, a prolonged duration of organ replacement therapy and consequently an increased length of stay in the ICU [58]. Vanderheyden and associates carried out a cost analysis exploring the magnitude and drivers of the cost difference that resulted from the early parenteral nutritional strategy [59]. The investigators developed a cost tree based on the treatment allocation for the study patients and reported healthcare costs for the excess costgenerating events (new infections and prolonged ICU stay) that were identified. These two groups represented one-quarter of the ICU population each but almost onehalf of the costs each. The investigators found that late parenteral nutrition reduced mean total incremental health costs by $€ 1,110$. The higher costs associated with the early parenteral nutrition group were mostly brought about by the higher costs for pharmacy, blood products and clinical chemistry. While the value of a formal costeffectiveness analysis of early parenteral nutrition when the effectiveness analysis showed harm is questionable, the study provides significant detailed information on the cost structures of intensive care.

\section{Abbreviations}

APACHE, Acute Physiology and Chronic Health Evaluation; ARDS, acute respiratory distress syndrome; $\mathrm{Cl}$, confidence interval; $\mathrm{HRQOL}$, health-related quality of life; OR, odds ratio; PTSD, post-traumatic stress disorder.

\section{Competing interests}

The authors declare that they have no competing interests.

\section{Author details}

'Medical Intensive Care Unit, Respiratory Institute, Cleveland Clinic Foundation, 9500 Euclid Avenue, Cleveland, $\mathrm{OH} 44195$, USA. ${ }^{2}$ Department of Medicine, University of Toronto School of Medicine, Toronto, Ontario, Canada. ${ }^{3}$ Department of Medicine, Sunnybrook Health Sciences Centre, 2075 Bayview Avenue, Toronto ON, Canada, M4N3M5.

Published: 22 November 2013

\section{References}

1. Rubenfeld GD, Angus DC, Pinsky MR, Curtis JR, Connors AF, Jr, Bernard GR: Outcomes research in critical care: results of the American Thoracic Society Critical Care Assembly Workshop on Outcomes Research. The Members of the Outcomes Research Workshop. Am J Respir Crit Care Med 1999, 160:358-367.

2. Ewig S, Woodhead M, Torres A: Towards a sensible comprehension of severe community-acquired pneumonia. Intensive Care Med 2011, 37:214-223.

3. Renaud B, Labarère J, Coma E, Santin A, Hayon J, Gurgui M, Camus N, Roupie E, Hémery F, Hervé J, Salloum M, Fine MJ, Brun-Buisson C: Risk stratification of early admission to the intensive care unit of patients with no major criteria of severe community-acquired pneumonia: development of an international prediction rule. Crit Care 2009, 13:R54

4. Charles PG, Wolfe R, Whitby M, Fine MJ, Fuller AJ, Stirling R, Wright AA, Ramirez JA, Christiansen KJ, Waterer GW, Pierce RJ, Armstrong JG, Korman TM, Holmes P, Obrosky DS, Peyrani P, Johnson B, Hooy M; Australian CommunityAcquired Pneumonia Study Collaboration; Grayson ML: SMART-COP: a tool for predicting the need for intensive respiratory or vasopressor support in community-acquired pneumonia. Clin Infect Dis 2008, 47:375-384.

5. Marti C, Garin N, Grosgurin O, Poncet A, Combescure C, Carballo S, Perrier A: Prediction of severe community-acquired pneumonia: a systematic review and meta-analysis. Crit Care 2012, 16:R141.

6. Thomsen RW, Riis A, Kornum JB, Christensen S, Johnsen SP, Sorensen HT: Preadmission use of statins and outcomes after hospitalization with pneumonia: population-based cohort study of 29,900 patients. Arch Intern Med 2008, 168:2081-2087.

7. Majumdar SR, McAlister FA, Eurich DT, Padwal RS, Marrie TJ: Statins and outcomes in patients admitted to hospital with community acquired pneumonia: population based prospective cohort study. BMJ 2006, 333:999.

8. Nielsen AG, Nielsen RB, Riis AH, Johnsen SP, Sorensen HT, Thomsen RW: The impact of statin use on pneumonia risk and outcome: a combined population-based case-control and cohort study. Crit Care 2012, 16:R122.

9. Yende S, Milbrandt EB, Kellum JA, Kong L, Delude RL, Weissfeld LA, Angus DC: Understanding the potential role of statins in pneumonia and sepsis. Crit Care Med 2011, 39:1871-1878.

10. Kojicic M, Li G, Hanson AC, Lee KM, Thakur L, Vedre J, Ahmed A, Baddour LM, Ryu JH, Gajic O: Risk factors for the development of acute lung injury in patients with infectious pneumonia. Crit Care 2012, 16:R46.

11. Adhikari NK, Fowler RA, Bhagwanjee S, Rubenfeld GD: Critical care and the global burden of critical illness in adults. Lancet 2010, 376:1339-1346.

12. Hutchings A, Durand MA, Grieve R, Harrison D, Rowan K, Green J, Cairns J, Black N: Evaluation of modernisation of adult critical care services in England: time series and cost effectiveness analysis. BMJ 2009, 339:b4353.

13. Duke GJ, Green JV: Outcome of critically ill patients undergoing interhospital transfer. Med J Aust 2001, 174:122-125.

14. Ligtenberg JJ, Arnold LG, Stienstra Y, van der Werf TS, Meertens JH, Tulleken JE, Zijlstra JG: Quality of interhospital transport of critically ill patients: a prospective audit. Crit Care 2005, 9:R446-R451.

15. Seymour CW, Kahn JM, Schwab CW, Fuchs BD: Adverse events during rotary-wing transport of mechanically ventilated patients: a retrospective cohort study. Crit Care 2008, 12:R71.

16. Barratt H, Harrison DA, Rowan KM, Raine R: Effect of non-clinical interhospital critical care unit to unit transfer of critically ill patients: a propensity-matched cohort analysis. Crit Care 2012, 16:R179.

17. O'Callaghan DJ, Jayia P, Vaughan-Huxley E, Gribbon M, Templeton M, Skipworth JR, Gordon AC: An observational study to determine the effect of delayed admission to the intensive care unit on patient outcome. Crit Care 2012, 16:R173.

18. Metcalfe MA, Sloggett A, McPherson K: Mortality among appropriately referred patients refused admission to intensive-care units. Lancet 1997 350:7-11.

19. Webb SA, Pettila V, Seppelt I, Bellomo R, Bailey M, Cooper DJ, Cretikos M, Davies AR, Finfer S, Harrigan PW, Hart GK, Howe B, Iredell JR, MCArthur C, Mitchell I, Morrison S, Nichol AD, Paterson DL, Peake S, Richards B, Stephens D, Turner A, Yung M: Critical care services and 2009 H1N1 influenza in Australia and New Zealand. N Eng/ J Med 2009, 361:1925-1934.

20. Christian MD, Joynt GM, Hick JL, Colvin J, Danis M, Sprung CL: Chapter 7. Critical care triage. Recommendations and standard operating procedures for intensive care unit and hospital preparations for an influenza epidemic 
or mass disaster. Intensive Care Med 2010, 36(Suppl 1):S55-S64

21. Richard JC, Pham T, Brun-Buisson C, Reignier J, Mercat A, Beduneau G, Regnier B, Mourvillier B, Guitton C, Castanier M, Combes A, Tulzo YL, Brochard L; REVA Study Group: Interest of a simple on-line screening registry for measuring ICU burden related to an influenza pandemic. Crit Care 2012, 16:R118.

22. Chan PS, Jain R, Nallmothu BK, Berg RA, Sasson C: Rapid response teams: a systematic review and meta-analysis. Arch Intern Med 2010, 170:18-26.

23. Calzavacca P, Licari E, Tee A, Egi M, Downey A, Quach J, Haase-Fielitz A, Haase M, Bellomo R: The impact of Rapid Response System on delayed emergency team activation patient characteristics and outcomes a follow-up study. Resuscitation 2010, 81:31-35.

24. Tobin AE, Santamaria JD: Medical emergency teams are associated with reduced mortality across a major metropolitan health network after two years service: a retrospective study using government administrative data. Crit Care 2012, 16:R210

25. Valentin A, Jordan B, Lang T, Hiesmayr M, Metnitz PG: Gender-related differences in intensive care: a multiple-center cohort study of therapeutic interventions and outcome in critically ill patients. Crit Care Med 2003, 31:1901-1907.

26. Fowler RA, Sabur N, Li P, Juurlink DN, Pinto R, Hladunewich MA, Adhikari NK, Sibbald WJ, Martin CM: Sex-and age-based differences in the delivery and outcomes of critical care. CMA/ 2007, 177:1513-1519.

27. Romo H, Amaral AC, Vincent JL: Effect of patient sex on intensive care unit survival. Arch Intern Med 2004, 164:61-65.

28. Mahmood K, Eldeirawi K, Wahidi MM: Association of gender with outcomes in critically ill patients. Crit Care 2012, 16:R92.

29. Castro RA, Angus DC, Hong SY, Lee C, Weissfeld LA, Clermont G, Rosengart MR: Light and the outcome of the critically ill: an observational cohort study. Crit Care 2012, 16:R132.

30. Ely EW, Shintani A, Truman B, Speroff T, Gordon SM, Harrell FE, Jr, Inouye SK, Bernard GR, Dittus RS: Delirium as a predictor of mortality in mechanically ventilated patients in the intensive care unit. JAMA 2004, 291:1753-1762.

31. Thomason JW, Shintani A, Peterson JF, Pun BT, Jackson JC, Ely EW: Intensive care unit delirium is an independent predictor of longer hospital stay: a prospective analysis of 261 non-ventilated patients. Crit Care 2005, 9:R375-R381.

32. van Eijk MM, van Marum RJ, Klijn IA, de Wit N, Kesecioglu J, Slooter AJ: Comparison of delirium assessment tools in a mixed intensive care unit. Crit Care Med 2009, 37:1881-1885

33. Gusmao-Flores D, Fiqueira Salluh Jl, Chalhub RA, Quarantini LC The confusion assessment method for the intensive care unit (CAM-ICU) and intensive care delirium screening checklist (ICDSC) for the diagnosis of delirium: a systematic review and meta-analysis of clinical studies. Crit Care 2012, 16:R115.

34. Girard TD, Kress JP, Fuchs BD, Thomason JW, Schweickert WD, Pun BT, Taichman DB, Dunn JG, Pohlman AS, Kinniry PA, Jackson JC, Canonico AE, Light RW, Shintani AK, Thompson JL, Gordon SM, Hall JB, Dittus RS, Bernard GR, Ely EW: Efficacy and safety of a paired sedation and ventilator weaning protocol for mechanically ventilated patients in intensive care (Awakening and Breathing Controlled trial): a randomised controlled trial. Lancet 2008, 371:126-134.

35. Brummel NE, Girard TD: Preventing delirium in the intensive care unit. Crit Care Clin 2013, 29:51-65.

36. Van Rompaey B, Elseviers MM, Van Drom W, Fromont V, Jorens PG: The effect of earplugs during the night on the onset of delirium and sleep perception: a randomized controlled trial in intensive care patients. Crit Care 2012, 16:R73.

37. Kress JP, Pohlman AS, O'Connor MF, Hall JB: Daily interruption of sedative infusions in critically ill patients undergoing mechanical ventilation. N Engl J Med 2000, 342:1471-1477.

38. Prasad M, Christie JD, Bellamy SL, Rubenfeld GD, Kahn JM: The availability of clinical protocols in US teaching intensive care units. J Crit Care 2010, 25:610-619.

39. Mehta S, Burry L, Fischer S, Martinez-Motta JC, Hallett D, Bowman D, Wong C, Meade MO, Stewart TE, Cook DJ: Canadian survey of the use of sedatives, analgesics, and neuromuscular blocking agents in critically ill patients. Crit Care Med 2006, 34:374-380

40. Dale CR, Hayden SJ, Treggiari MM, Curtis JR, Seymour CW, Yanez ND, 3rd, Fan VS: Association between hospital volume and network membership and an analgesia, sedation and delirium order set quality score: a cohort study. Crit Care 2012, 16:R106.
41. Oeyen SG, Vandijck DM, Benoit DD, Annemans L, Decruyenaere JM: Quality of life after intensive care: a systematic review of the literature. Crit Care Med 2010, 38:2386-2400.

42. Herridge MS, Tansey CM, Matte A, Tomlinson G, Diaz-Granados N, Cooper A, Guest CB, Mazer CD, Mehta S, Stewart TE, Kudlow P, Cook D, Slutsky AS, Cheung AM; Canadian Critical Care Trials Group: Functional disability 5 years after acute respiratory distress syndrome. N Engl J Med 2011, 364:1293-1304.

43. Oeyen S, Vandijck D, Benoit D, Decruyenaere J, Annemans L, Hoste E: Long-term outcome after acute kidney injury in critically-ill patients. Acta Clin Belg Suppl 2007, 2:337-340.

44. Luyt $C E$, Combes A, Becquemin MH, Beigelman-Aubry C, Hatem S, Brun AL, Zraik N, Carrat F, Grenier PA, Richard JC, Mercat A, Brochard L, Brun-Buisson C, Chastre J; REVA Study Group: Long-term outcomes of pandemic 2009 influenza A(H1N1)-associated severe ARDS. Chest 2012, 142:583-592.

45. Vaara ST, Pettila V, Reinikainen M, Kaukonen KM: Population-based incidence, mortality and quality of life in critically ill patients treated with renal replacement therapy: a nationwide retrospective cohort study in finnish intensive care units. Crit Care 2012, 16:R13.

46. Peek GJ, Mugford M, Tiruvoipati R, Wilson A, Allen E, Thalanany MM, Hibbert CL, Truesdale A, Clemens F, Cooper N, Firmin RK, Elbourne D; CESAR Trial Collaboration: Efficacy and economic assessment of conventional ventilatory support versus extracorporeal membrane oxygenation for severe adult respiratory failure (CESAR): a multicentre randomised controlled trial. Lancet 2009, 374:1351-1363.

47. Hodgson CL, Hayes K, Everard T, Nichol A, Davies AR, Bailey MJ, Tuxen DV, Cooper DJ, Pellegrino V: Long-term quality of life in patients with acute respiratory distress syndrome requiring extracorporeal membrane oxygenation for refractory hypoxaemia. Crit Care 2012, 16:R202.

48. Davydow DS, Gifford JM, Desai SV, Needham DM, Bienvenu OJ: Posttraumatic stress disorder in general intensive care unit survivors: a systematic review. Gen Hosp Psychiatry 2008, 30:421-434.

49. Davydow DS, Gifford JM, Desai SV, Bienvenu OJ, Needham DM: Depression in general intensive care unit survivors: a systematic review. Intensive Care Med 2009, 35:796-809.

50. Wade DM, Howell DC, Weinman JA, Hardy RJ, Mythen MG, Brewin CR, Borja-Boluda S, Matejowsky CF, Raine RA: Investigating risk factors for psychological morbidity three months after intensive care: a prospective cohort study. Crit Care 2012, 16:R192.

51. Schandl A, Bottai M, Hellgren E, Sundin O, Sackey P: Gender differences in psychological morbidity and treatment in intensive care survivors a cohort study. Crit Care 2012, 16:R80.

52. Nassar AP, Jr, Mocelin AO, Nunes AL, Giannini FP, Brauer L, Andrade FM, Dias CA: Caution when using prognostic models: a prospective comparison of 3 recent prognostic models. J Crit Care 2012, 27:423.e1-e7.

53. Patel PA, Grant BJ: Application of mortality prediction systems to individual intensive care units. Intensive Care Med 1999, 25:977-982

54. Huttunen R, Syrjanen J, Vuento R, Hurme M, Huhtala H, Laine J, Pessi T, Aittoniemi J: Plasma level of soluble urokinase-type plasminogen activator receptor as a predictor of disease severity and case fatality in patients with bacteraemia: a prospective cohort study. J Intern Med 2011, 270:32-40

55. Giamarellos-Bourboulis EJ, Norrby-Teglund A, Mylona V, Savva A, Tsangaris I, Dimopoulou I, Mouktaroudi M, Raftogiannis M, Georgitsi M, Linnér A, Adamis G, Antonopoulou A, Apostolidou E, Chrisofos M, Katsenos C, Koutelidakis I, Kotzampassi K, Koratzanis G, Koupetori M, Kritselis I, Lymberopoulou K, Mandragos K, Marioli A, Sundén-Cullberg J, Mega A, Prekates A, Routsi C, Gogos C, Treutiger CJ, Armaganidis A, Dimopoulos G: Risk assessment in sepsis: a new prognostication rule by APACHE II score and serum soluble urokinase plasminogen activator receptor. Crit Care 2012, 16:R149.

56. Kleinpell RM, Ely EW, Grabenkort R: Nurse practitioners and physician assistants in the intensive care unit: an evidence-based review. Crit Care Med 2008, 36:2888-2897.

57. Carpenter DL, Gregg SR, Owens DS, Buchman TG, Coopersmith CM: Patient-care time allocation by nurse practitioners and physician assistants in the intensive care unit. Crit Care 2012, 16:R27.

58. Casaer MP, Mesotten D, Hermans G, Wouters PJ, Schetz M, Meyfroidt G, Van Cromphaut S, Ingels C, Meersseman P, Muller J, Vlasselaers D, Debaveye Y, Desmet L, Dubois J, Van Assche A, Vanderheyden S, Wilmer A, Van den Berghe G: Early versus late parenteral nutrition in critically ill adults. N Engl J Med 2011, 365:506-517.

59. Vanderheyden S, Casaer MP, Kesteloot K, Simoens S, De Rijdt T, Peers G, 
Wouters PJ, Coenegrachts J, Grieten T, Polders K, Maes A, Wilmer A, Dubois J, Van den Berghe G, Mesotten D: Early versus late parenteral nutrition in ICU patients: cost analysis of the EPaNIC trial. Crit Care 2012, 16:R96. doi:10.1186/cc12759

Cite this article as: Duggal A, Rubenfeld G: Year in review 2012: Critical

Care -management. Critical Care 2013, 17:250. 